\title{
Diversidad y polimorfismo en el género Exophiala: manejo de las especies comunes en el laboratorio de baja complejidad
}

\author{
(Diversity and polimorphism in the genus Exophiala: handling of common species \\ in the low complexity laboratory)
}

Eduardo Piontelli L.

Recibido: $14-05-13$

Aprobado: 23-05-13

Palabras clave: Exophiala, diversidad, taxonomía.

Key words: Exophiala, diversity, taxonomy.

\section{RESUMEN}

Exophiala es un género fúngico poco común, conocido como integrante de las levaduras negras y sus respectivas formas filamentosas que pertenece al orden Chaetothyriales. Estos hongos son causantes de cromoblastomicosis o diferentes tipos de faeohifomicosis en pacientes sanos o con compromiso inmune (cutáneas, subcutáneas, diseminadas y quistes de faeohifomicosis). Sus miembros son a menudo difíciles de clasificar a nivel de especie solo por métodos fenéticos, debido a su polimorfismo en cultivo y la gran diversidad molecular que exhiben, la cual se confirma en la revisión de la literatura en estos últimos 15 años. El objetivo de este estudio, se basa en la descripción y recopilación de las especies más comunes del género, presente en ambientes diversos y específicos, con especial atención a los principales aportes morfo fisiológicos útiles en su diagóstico en un laboratorio de baja complejidad, sin olvidar que debido a su alto polimorfismo y la aparente similitud entre especie, el micólogo debe confirmar su hallazgo mediante el envío de su cepa a un laboratorio de referencia internacional para evitar el subdiagnóstico.

\section{Aspectos Generales}

Un buen número de especies consideradas como levaduras negras y sus anamorfos filamentosos respectivos pertenecen al género Exophiala (Pezizomycotina, Chaetothyriales, Herpotrichellaceae, con teleomorfo en Capronia), son agentes cosmopolitas y comunes de micosis (faeohifomicosis) humanas y animales (Naja et al., 1986; Neumeister et al., 1995; De Hoog et al., 2002). Las especies de Exophiala, por su lento crecimiento, son difíciles de encontrar en el ambiente y necesitan medios especiales de aislamiento y por ende, no son aisladas en tiempos cortos de incubación.

Carmichael (1966), introduce el género Exophiala mediante un reporte de una lesión cerebral en salmones

\section{ABSTRACT}

Exophiala is an uncommon fungic genus, known as integrant of black yeast and its filamentous relatives that belong to the Chaetothyriales order.

This fungi produce cromoblastomicosis or different kinds of phaeohyfomycosis in healthy patients or immunocompromissed patients (cutaneous, subcutaneous, scattered and phaeohyfomycosis's cysts). Its members are often hard to classify to species by only using phenetics methods, because they present polimorfisms in culture and shows great molecular diversity, wich is confirmed in the review of literature in the last 15 years. The aim of this study is the description and recopilation of the most common species of the genus, that is present in a variety or specific enviroments, with special enphasis onto the principal morfo-physiologic contributions that are usefull to diagnose in a low complexity laboratory, given its high polymorfism and similar look between species, the mycologist must confirm its strain by sending it to an international reference laboratory in order to avoid underdiagnosis.

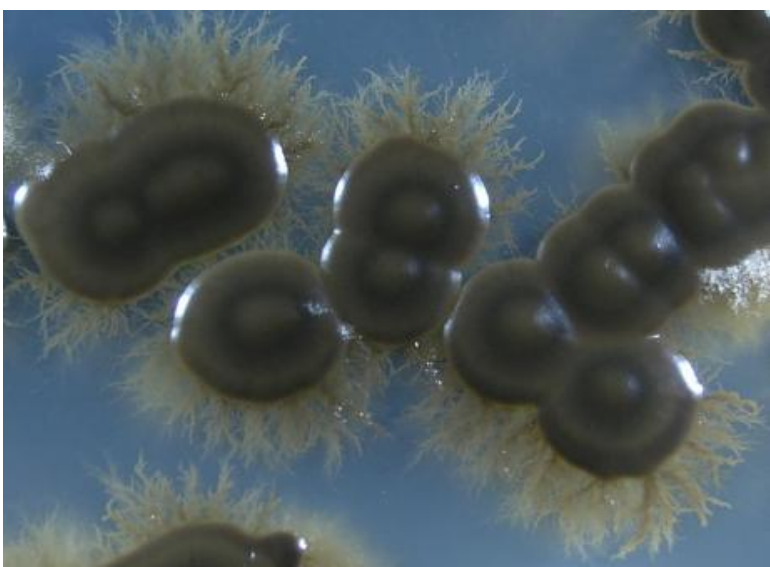

Fig.1. Exophiala dermatitidis colonias levaduriformes a gran aumento, mostrando micelio vegetativo sumergido (Tomado de: www.fnp/zen.cz/mykoatlas/.../E_dermatitidis.htm) 
Diversidad y polimorfismo en el género Exophiala: manejo de las especies comunes en el laboratorio de baja complejidad -E. Piontelli.

(Salmo clarkii), llamando a la especie $\boldsymbol{E}$. salmonis una infección que se extendió en proporciones epizóticas con un grado de mortalidad de hasta un $40 \%$ en criaderos de salmón en Calgary (Canada), que en años posteriores se extendió a otros salmones del Atlántico (Salmo salar), mientras en Noruega (Langvad et al.,1985), reportaron mortalidades de hasta un $50 \%$ en ( $S$. salar) causadas por otra especies del género como Exophiala psychrophila (Pedersen \& Langvad 1989). Esta situación llama la atención debido a que en el Reino fúngico en general las especies no termotolerantes son en general saprotrofas, sin capacidades infectivas y estas últimas habilidades en los humanos son raras, en especial debido a que algunas de estas especies no crecen más que a $33^{\circ} \mathrm{C}$ (máximo $36^{\circ} \mathrm{C}$ ), sin embargo, pueden causar zoonosis en animales de sangre caliente en zonas subtropicales (Boeger et al., 2005-2007) (Ver Tabla 1).

\section{Aspectos Ecológicos}

El género en general tiene una habilidad única para adaptarse a los ambientes extremos (desde la exposición a productos químicos tóxicos, altas temperaturas, escasez de nutrientes, condiciones ácidas o secas). A pesar de ésto, presenta un no despreciable potencial oportunístico en humanos, que se diferencia de otros hongos oportunistas por causar infecciones en individuos aparentemente sanos (Horrie \& de Hoog, 1999) y ocasionalmente en individuos con compromiso inmune. Además estos microrganismos, más que otros grupos fúngicos, se han reportado desde ambientes ricos en compuestos aromáticos (madera tratada con creosota), lo que indica que su acumulación promueve su desarrollo (Zang et al, 2010).

Su distribución es amplia en hábitat tóxicos 0 pobres en nutrientes, suelos industriales contaminados asociados generalmente al hombre, como en ambientes internos (Zalar et al., 2011), en aguas saladas o no, incluso en agua potable municipal como: $E$. castellani, $E$. jeanselmei, $\boldsymbol{E}$. spinifera, $\boldsymbol{E}$.mesophila, etc.(Göttlich et al., 2002; Porteus et al.,2003), las salas de baños de las casas 0 aún en ambientes microextremos como los sauna (Matos et al., 2002), cuando se emplean métodos especiales de aislamiento (Lian \& de Hoog, 2010; Biedunkiewicz \& Schulz, 2012). La taxonomía de las especies de Exophiala psicrofílicas en aguas, no se ha estudiado en gran escala, sin enbargo, De Hoog et al.,(2011) confirman que todas las especies acuáticas de Exophiala pertenecn a las Chaetothyriales. Otro grupo de hongos negros comunes en aguas municipales potables son los integrantes del género Cadophora, anamorfo de Pyrenopeziza en los Helotiales (Göttlich et al., 2002).

Existe una fuerte relación de su presencia cuando se asocian con hidrocarburos monoaromáticos, donde presentan ventajas competitivas (Prenafeta-Boldú et al., 2006; Vicente et al., 2008; Zhao et al., 2010). No está totalmente clara la posible vía de infección de estos hongos, sin embargo, como sugieren Lian \& de Hoog (2010), el riesgo más probable es la inoculación cutánea, después de una humidificación y abrasión de la piel (para el aislamiento del ambiente en suelos contaminados con hidrocarburos, vea Satow et al.,( 2008).

Este taxón exhibe un relativo alto grado de diversidad molecular ya sea dentro del mismo género, como en su posición dentro del orden, lo que indica la radiación de los taxas dentro de un corto período evolucionario de tiempo (De Hoog et al., 1997; Haase et al., 1999). La morfología es poco desarollada en estos hongos y cuando se presentan estructuras similares microscópicas, estas pueden expresarse al mismo tiempo en especies filogenéticamente remotas (Haase et al., 1999). A pesar que los disgnósticos morfológicos y fisiológicos son aún útiles (De Hoog \& Haase, 1993), debido a que algunas especies tienen marcados caracteres fenéticos como los largos conidióforos de $\boldsymbol{E}$. spinifera, o la termotolerancia y la ausencia de asimilación de nitritos en $\boldsymbol{E}$. dermatitidis, la mayoría de las especies son en buena medida morfológicamente variables, debido a sus complicados ciclos de vida (De Hoog et al ., 1994).

\section{Teleomorfo}

A pesar que el telomorfo de las levaduras negras como el género Capronia fue descrito por Saccardo (1883), o aún unos años anteriores, con la especie tipo a C. sexdecimospora, su anamorfo fue descrito recientemente (Carmichael,1966). Algunos géneros semejante al anamorfo de Exophiala, fueron encontrados anteriormente en la literatura con otros nombres (ver; De Hoog et al., 2011).

\section{Importancia clínica y especies involucradas}

De Hoog et al., (2011) comentan que los animales acuáticos se infectan más frecuentemente por hongos Chaetothyriales que los terrestres. La temperatura del hospedador puede ser correlacionada con el máximo crecimiento en temperatura de las especies invasivas en cada una de los clados. En términos generales, los clados que incluyen especies capaces de crecer bien a temperaturas sobre los $36-37^{\circ} \mathrm{C}$ (los clados bantiana, dermatitidis y jeanselmei) pueden causar infecciones sistemicas 0 diseminadas en humanos, mientras aquellas con un máximo de temperatura alrededor de los 36$37^{\circ} \mathrm{C}$ (Los clados carrionii y europaea), causan infecciones subcutaneas y superficiales. Las especies del clado salmonis tienen una máxima temperatura de $27-33^{\circ} \mathrm{C}$, en forma excepcional $36^{\circ} \mathrm{C}$, y pueden causar infecciones superficiales, la mayor parte apenas invasivas (Li et al., 2009; Saunte et al., 2011) (ver: Tabla.1). El potencial patogénico hacia los animales inmunocom-petentes, se obseva en casi todos los mayores clados en los Chaetothyriales, donde su diversidad de especies y su específica ecología los 
Diversidad y polimorisismo en el género Exophiala: manejo de las especies comunes en el laboratorio de baja complejidad -E. Piontelli.

convierten en un grupo de considerable relevancia médica, muy similar al grupo de los Onygenales (De Hoog et al., 2003).

Los clados ancestrales con incierta afiliación, contienen predominantemente especies que viven sobre rocas, las cuales solo ocasionalmente se presentan en infecciones cutáneas suaves. La patogenicidad se observa particularmente en peces, anfibios y mamíferos en particular en humanos, mientras las infecciones en reptiles y pájaros no se observan, debido a su gruesa piel seca que carece de glándulas de transpiración, mientras los humanos, tienen piel fina, protegida, predominantemente con pocos pelos y provistas de glandulas de transpiración para refrescarse.

Los principales agentes causantes de185 infecciones sistémicas o cutáneas en USA, por integrantes del género Exophiala (Zeng et al., 2007), permiten apreciar en una zona geográfica extensa la dominancia o frecuencia de presencia de este genero como oportunista. En orden decreciente se aislaron: $\boldsymbol{E}$. dermatitidis, E.xenobiotica, $E$. oligosperma, $E$. lecanii-corni, $E$. phaeomuriformis. Las especies de Exophiala que fueron repetidamente aisladas de infecciones profundas(39.9\%), comprometieron pulmones, fluidos pleurales, esputo, órganos digestivos (estómago, intestino, bilis), corazón, cerebro, bazo, médula ósea, sangre,fluidos de diálisis, nodos linfáticos, articulaciones, pecho, oído medio, garganta y tejidos intraoculares. Alrededor de un 38.3\% de las especies de Exophiala fueron agentes de infecciones cutáneas, incluyendo la piel, menbranas mucosas, uñas y lesiones del epitelio corneal, pelo 0 infecciones subcutáneas(12\%), incluyendo senos paranasales, micetomas y quistes subcutáneos.

Las infecciones sistémicas, fueron causadas principalmente por $\boldsymbol{E}$. dermatitidis, $\boldsymbol{E}$. oligosperma, $\boldsymbol{E}$. phaeomuriformis, $E$. xenobiotica y E. lecanii-corni. Mientras las especies $\boldsymbol{E}$. bergeri, $\boldsymbol{E}$. spinifera, $\boldsymbol{E}$. jeanselmei, E.mesophila y $E$. attenuata, mayormente inducen infecciones cutáneas y subcutáneas. Estos autores sostienen que su listado de especies oportunistas de Exophiala en climas temperados es bastante completo, sin embargo, aún falta que describir un buen número de especies. Recientemente se reportan los 2 primeros casos de onicomicosis causadas por $\boldsymbol{E}$. bergeri y $\boldsymbol{E}$. oligosperma (Woo et al., 2013).

El concepto de especie en Exophiala ha cambiado considerablemente después de la aplicación de los métodos moleculares en los últimos 15 años, en especial en el grupo o clado $\boldsymbol{E}$. jeanselmei, el cual incluye un variado número de especies crípticas tales como: E.heteromorpha, E. Iecanii-corni, E.oligosperma y $E$. xenobiotica, además de E.jeanselmei sensu stricto. (Haase et al., 1999; De Hoog et al., 2000-2003-2006). La reciente especie descrita E.xenobiotica parece ser la levadura negra más frecuente y difiere de $\boldsymbol{E}$. jeanselmei, a nivel molecular y por presentar diferentes sitios de
Tabla 1. Chaetothyriales, temperatura máxima de crecimiento $\left({ }^{\circ} \mathrm{C}\right)$ y enfermedades en mamíferos.

\begin{tabular}{|lcc|}
\hline Clado bantiana & $37-40^{\circ} \mathrm{C}$ & Diseminadas \\
Clado dermatitidis & $36-42^{\circ} \mathrm{C}$ & Diseminadas \\
Clado jeanselmei & $36-38^{\circ} \mathrm{C}$ & Diseminadas \\
Clado carrioni & $36-37^{\circ} \mathrm{C}$ & Subcutáneas \\
Clado europea & $37^{\circ} \mathrm{C}$ & Superficial cutáneas \\
Clado salmonis & $27-33(36)^{\circ} \mathrm{C}$ & Superficial \\
Clado roca & $?$ & Superficial \\
\hline
\end{tabular}

infección (de Hoog et al., 2006).

El bajo diagnóstico de $\boldsymbol{E}$. xenobiotica y $\boldsymbol{E}$. oligosperma (ambas derivadas de E.jeanselmei sensu, lato) las cuales son mucho más comunes en infecciones subcutáneas que $\boldsymbol{E}$. jeanselmei sensu stricto, deben sus nuevas nominaciones, seguramente al desarrollo de la taxonomía molecular y a la redescripción de estos taxas posteriormente a su depósito en los centros de referencia de las levaduras negras, los cuales solo se denominaban generalmente como "E. jeanselmei" o "Exophiala sp." (Zeng et al., 2007; Badali et al., 2010). Debido a esto, el subdiagnóstico de las variadas infecciones por Exophiala es un problema mundial, dificultando el significado clínico de las especies individuales, ya sea en los casos sistémicos 0 superficiales (Zeng et al., 2007).

Las infecciones humanas causadas por estas especies, pueden separarse en tres tipos: superficiales cutáneas y subcutáneas o viscerales/sistémicas (Matsumoto et al., 1993), a pesar que la mayoría de los casos se incluyen en las primeras 2 categorías (Zeng et al., 2007). Algunos casos de neumonia, fungemia, infecciones del sistema nervioso central, endocarditis y peritonitis también se han reportado (Tseng et al., 2005; Ozawa et al., 2007; Langvad et al., 2009). Las micosis sistémicas se presentan mayoritariamente en pacientes con factores predisponentes, como transplantes de órganos sólidos, leucemia, fibrosis quística, HIV y diálisis (Langvad et al., 2009). También $\boldsymbol{E}$. dermatitidis y $\boldsymbol{E}$. oligosperma se presentan en infecciones cutáneas.

El género Exophiala incluye un alto numero de especies ampliamenmte distribuidas en la naturaleza; de las aproximadamente 30 especies reconocidas, 18 han sido aisladas desde humanos y hospederos animales, ya sea como colonizadores 0 agentes de enfermedades. El hecho que estas especies muestran características morfológicas y bioquímicas semjante entre ellas, como también con otros hongos relacionados causantes de enfermedades clínicas similares y que frecuentemente fallan en producir estructuras características de disgnóstico en cultivos, hace necesario recurrir en buena medida a las técnicas moleculares como complemento de las morfofisiológicas.

\section{Medios de aislamiento}

Para una buena preparación microscópica de las 
Diversidad y polimorisismo en el género Exophiala: manejo de las especies comunes en el laboratorio de baja complejidad -E. Piontelli.

colonias de Exophiala obtenidas de medios de cutivos diversos, SAB, MEA, PDA, etc, se emplea un trozo de agar(MEA) de más 0 menos $1 \mathrm{~cm}^{2}$, se coloca sobre un portaobjeto estéril, soportado por dos tubos de vidrio en $\checkmark$ dentro de un placa de petri que tiene en su fondo un papel filtro estéril. Se inocula en sus 4 extremos el trozo de agar y se cubre posteriormente con un cubreojeto estéril que sea más grande que el trozo de agar, luego se agregan 5-10 $\mathrm{ml}$ de agua estéril en el fondo de la placa para mantener la humedad y se cierra con la contratapa. Se incuba a temperatura ambiente por 5 a 14 días. Se retira luego el cubreobjeto y se monta en un nuevo portabjeto con ácido láctico previo a la observación microscópica.

Ya sea en (PDA) o (SGA), las colonias de Exophiala generalmente crecen restringidas, son

Tabla 2. Características diferenciales en algunas especies del género Exophiala (De Hoog et al., 2000)

\begin{tabular}{|c|c|c|c|c|c|c|c|c|c|}
\hline Perfil fisiológico y de asimilación & ${ }^{\star} \mathrm{EBE}$ & ECA & EDE & EJE & ELE & EMO & EPI & ESA & ESP \\
\hline Crecimiento a $35^{\circ} \mathrm{C}$ & + & + & + & + & + & $\mathrm{v}$ & - & + & + \\
\hline Crecimiento a $37^{\circ} \mathrm{C}$ & + & - & + & + & d/- & d/- & - & + & + \\
\hline Crecimiento a $40^{\circ} \mathrm{C}$ & - & - & + & - & - & - & - & - & - \\
\hline Cicloheximida 0,1\% & $\mathrm{d} /-$ & + & + & - & + & - & + & + & + \\
\hline Nitrato & + & + & - & + & + & + & + & + & + \\
\hline Glucosamina & + & $\mathrm{d} /-$ & - & + & + & + & + & + & + \\
\hline$\alpha$-Metil-D-glucósido & d/- & + & $\mathrm{d} / \mathrm{-}$ & - & + & + & + & + & + \\
\hline Melibiosa & + & + & + & - & + & + & + & + & + \\
\hline Lactosa & - & - & $d /-$ & - & + & - & + & - & - \\
\hline Eritritiol & - & + & + & + & + & + & + & + & + \\
\hline Xilitol & + & + & + & + & + & - & + & + & + \\
\hline Arabinitol & $+/ d$ & + & - & + & - & - & + & + & + \\
\hline Inositol & + & - & + & $d /-$ & - & - & $d /-$ & + & + \\
\hline Glucuronato & + & - & + & + & - & $d /-$ & + & - & + \\
\hline Galacturonato & $+/ d$ & - & $d /-$ & + & - & - & + & - & + \\
\hline Lactato & $\mathrm{v}$ & - & - & + & - & - & - & - & + \\
\hline
\end{tabular}

$\mathrm{EBE}=$ E.bergeri; $\mathrm{ECA}=$ E.castellani; $\mathrm{EDE}=$ E.dermatitidis; $\mathrm{EJE}=$ E.jeanselmei; $\mathrm{ELE}=$ E.lecnii-corni; $\mathrm{EMO}=$ E.moniliae; $\mathrm{EPI}=$ E.pisciphila; $\mathrm{ESA}=$ E.salmonis; $\mathrm{ESP}=$ E.spinifera.$+=$ buen crecimiento; $-=$ crecimiento nulo; $\mathrm{d}=$ crecimiento débil; $\mathrm{v}=$ crecimiento variable

Tabla 2. Clave fenética aproximada para las especies del clado E. spinifera* (De Hoog et al., 2003)

Características

ITS agrupación

1. Conidiogénesis preponderantemente anelídica Conidiogénesis preponderantemente simpodial

2. Conidióforos multicelulares erectos presentes, que son oscuros tanto como el micelio de soporte Conidióforos multicelulares erectos ausentes

3. Zonas aneladas largas con anelaciones con volantes tempranamente visibles E. spinifera Zonas aneladas inconspicuas, degeneradas .... E. attenuata

4. Células conidiógenas maduras en forma de cohete, levemente más oscuras que la hifa de soporte, con zonas aneladas regularmente, ahusadas ..... E. jeanselmei Células conidiógenas maduras de otro tipo que per-

manecen del mismo color que la hifa soportante

5. Célula conidiógenas intercalares, conidios que se producen desde hifas rastreras E. lecanii-corni Células conidiógenas intercalares y laterales, las ultimas son elongadas, en forma de frasco o cohete.

6. Células brotantes solamente; fragmentos hifales mayormente sin unamarcada conidiación . E. exophialae
Hifas que producen conidios preponderantes

7. Zonas aneladas minutas en forma de diente Zonas aneladas con apariencia de una incospicua

aplanada cicatriz .... 8

8. Grandes células semejantes a clamidosporas presentes E. nishimurae Células semejantes a clamidoporas ausentes ........... E. oligosperma

9. Conidióforos café oscuros de paredes gruesas presentes. 10

Conidióforos solo ligeramente oscuros que el micelio

remanente 11

10.Conidióforos no ramificados........................ Ramichl. anceps Conidióforos compuestos de un sistema ramificado basípetamente R. basitonum 11. Conidios ampliamente elipsoidales, café pálidos ......... R. aquaspersa Conidios cilíndricos, hialinos R. atrovirens; R.similis

* Para una confiable identificación de especies, son necesarias las secuencias de ITS DNAr. 
Diversidad y polimorfismo en el género Exophiala: manejo de las especies comunes en el laboratorio de baja complejidad -E. Piontelli.

viscosas 0 a lo sumo mucosas en el centro, oliváceas a grises a café-negro, con reverso oliváceo. Inicialmente la propagación es usualmente semejante a células de levaduras, que pronto se transforman en células germinando e hifas torulosas, antes de formar anchos filamentos. La presencia de micelio toruloso es característico para Exophiala, pero puede ser insignificante en las especies prevalentemente simpodiales de la clade. Exophiala tiene células conidiógenas anelídicas. La coexistencia de células conidiógenas anélídicas, simpodiales y/o fialídicas es conocida en varias especies, como ejemplo en $\boldsymbol{E}$. jeanselmei (annelídicas y simpodiales ) y en E.spinifera (annelídica/fialídica). Los halos significantes que se presentan alrededor de las células levaduriformes, son de ayuda para distinguir $\boldsymbol{E}$. spinifera de otras especies; $\boldsymbol{E}$. dermatitidis, fuera del clado $\boldsymbol{E}$. spinifera, es la única levadura negra que forma cápsula (Yurlova, N.A. \& de Hoog, 2002).

\section{Identificación Molecular}

Se emplean los análisis de secuencias de las regiones ITS1-2, 5, 8S y $28 \mathrm{~S}$ RNAr, asi como el factor de elongación 1-alfa y los genes de la beta tubulina (Zeng et al., 2007; Harris et al.,2009; Morio et al., 2012), como también secuenciación de (ITS) y Rpb1(Woo et al., 2013). Para algunos autores se presentan grandes problemas cuando se identifican las spp. de Exophiala por secuencias de ITS y prefieren usar DNA mitocondrial (Kawasaki et al., 2005) Los métodos de extracción se indican en el trabajo de Gerrits van den Ende \& de Hoog (1999).

De Hoog et al., (2011), mediante un gran número representativo de integrantes del orden Chaetothyriales pudieron determinar una cantidad aproximada de complejos de especies. Algunos de ellos corresponden con los grupos SSU (1-4) previamente reconocidos por Haase et al., (1999). Los grupos o clados aproximados son: el clado bantiana, carrionii, salmonis, europaea, dermatitidis, jeanselmei y algunos clados ancestrales. El grupo Haase-1 se reconoce como clado dermatitidis, Haase-2 es el clado bantiana, y Haase-3-4 corresponde a 2 agrupamientos como el clado jeanselmei. Ninguno de estos clados son morfologicamente homogeneos; los géneros anamórficos Cladophialophora, Cyphellophora, Exophiala, Fonsecaea y Rhinocladiella son todos polifiléticos dentro del orden Chaetothyriales.

\section{Taxonomía}

Exophiala (anteriormente denominada Wangiella) causante de faeohifomicosis, presenta una taxonomía que es controversial debido a que algunos investigadores aún prefieren clasificarla en la literatura en el género Wangiella.
Exophiala, es el principal género de las levaduras negras, que se encuentra como oportunista de los vertebrados. Se caracteriza por su conidiogénesis anelídica, que produce conidios en falsas cabezas mucosas; algunos cultivos son enteramente semejantes a levaduras (sinanamorfo Phaeococcomyces, actalmente $E$. exophialae), o forman collaretes fialídicos (sinanamorfo Phialophora), conidióforos simpodiales (sinanamorfo Rhinocladiella) o cadenas de conidios secos (sinanamorfo Cladophialophora). Clamidosporas o cuerpos esclerotiales pueden formarse a veces, ocasionalmente se presentan en su totalidad como mutantes meristemáticos (sinanamorfo Sarcinomyces). Varias de estas morfologías están representadas particularmente en las especies de origen acuático como el clado salmonis .

El género Exophiala incluye principalmente los complejos $E$. jeanselmei, $E$. dermatitidis y $E$. spinifera. El complejo $\boldsymbol{E}$. jeanselmei tiene células conidiógenas oscuras en forma de cohete sin conidióforos multicelulares. $\boldsymbol{E}$. spinifera, por el contrario de $\boldsymbol{E}$. jeanselmei, tiene conidióforos multicelulares y material capsular alrededor de las células brotantes. $\boldsymbol{E}$. dermatitidis, posee numerosos conidióforos y células conidiógenas ya sea intercalares o libres y en forma de frasco; no asimila los nitritos y nitratos y a veces es llamada aún $W$. dermatitidis(Shu et al., 2012).

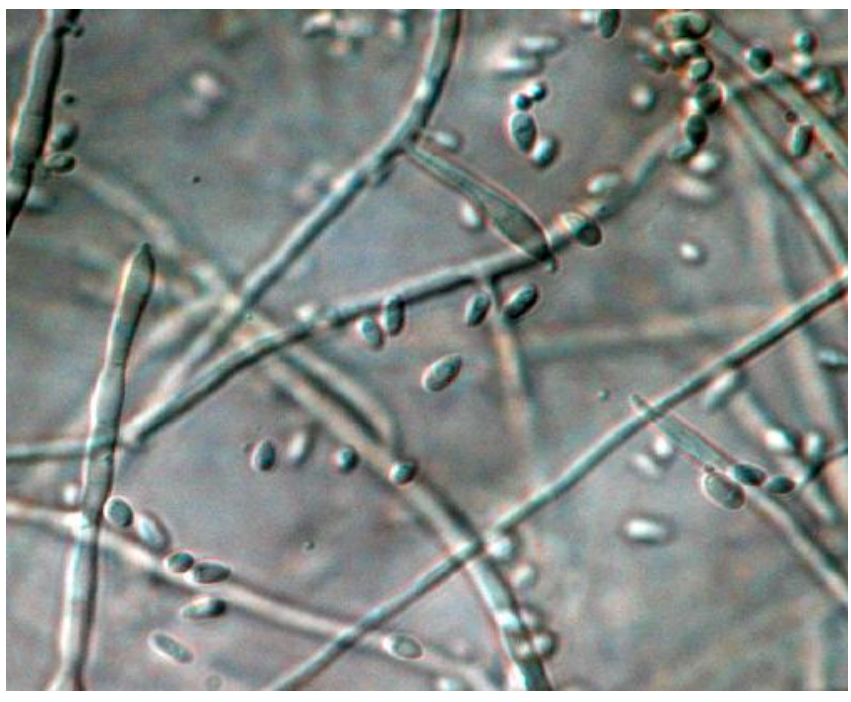

Figura 2. Exophiala jeanselmei. Células conidiógenas en forma de cohete y conidios dispersos. 
Diversidad y polimorfismo en el género Exophiala: manejo de las especies comunes en el laboratorio de baja complejidad -E. Piontelli.

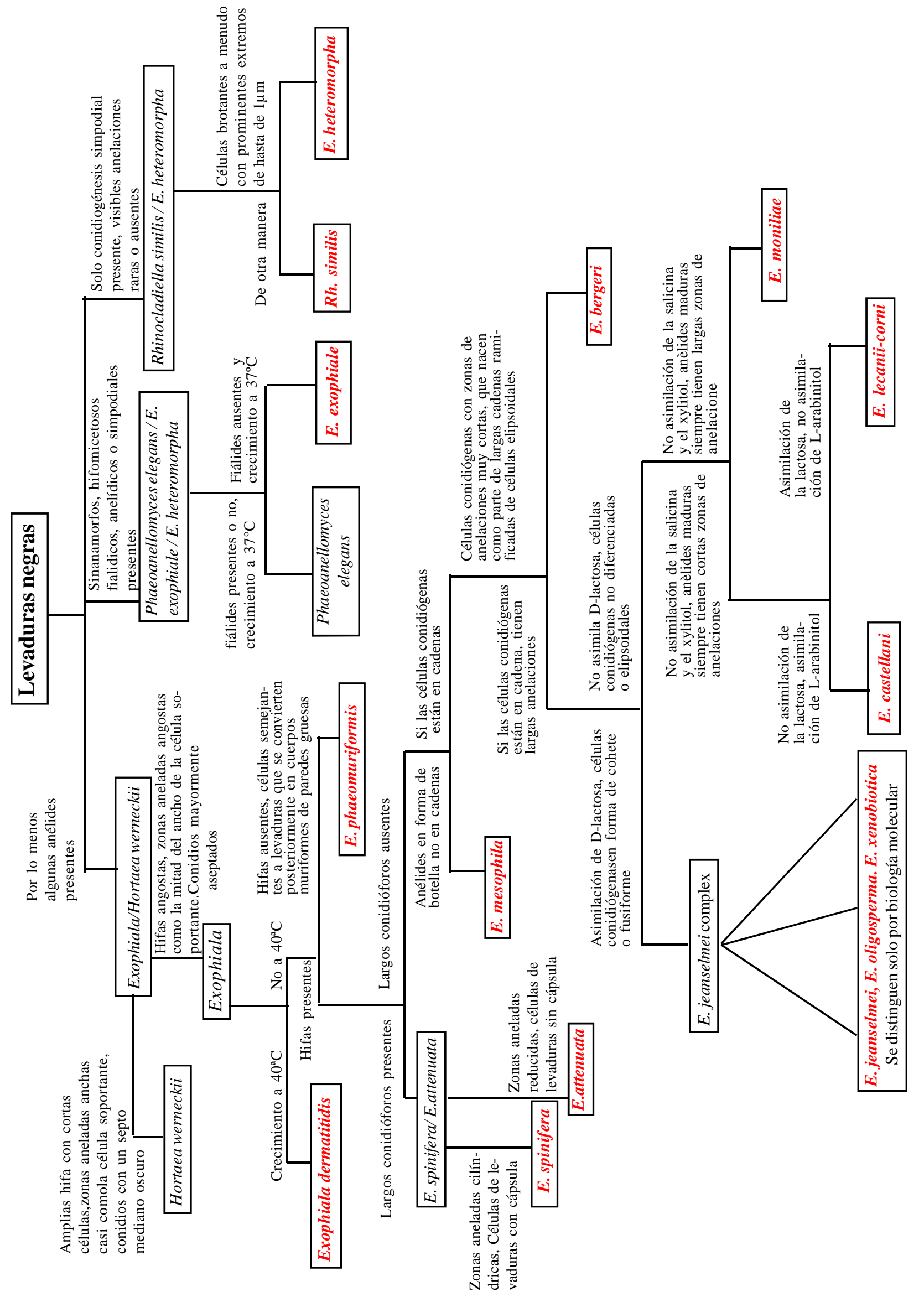

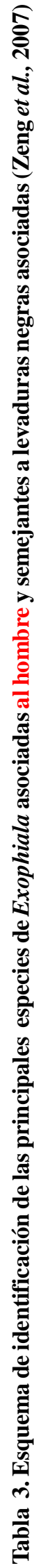




\section{Algunas especies oportunistas comunes del género Exophiala}

Exophiala bergeri Hasse \& de Hoog (Fig. 3).

$=$ Candida nigra canadensis Berger et al.

$=$ Torula bergeri Langeron

Características de cultivo: Colonias en PDA $25^{\circ} \mathrm{C}$ a menudo adheridas en largas cadenas, restringidas, blandas, olivaceas-oscuras a negras; margen lobado. Microscopía. Células gemando abundantes, cambiando a hifas torulosas. Hifas oliváceas pálidas, 1,5-2,5 $\mu \mathrm{m}$ de ancho, zonas aneladas cortas incospicuas, conidios ampliamente elipsoidales,variables, mayoritariamente 3-4 x 2-3 $\mu \mathrm{m}$.

Esta especie es morfológicamente similar a E.castellani (=E mansoni sensu de Hoog), de la cual se separa en base a datos moleculares. En general, las zonas aneladas son un tanto pequeñas, con menos adornos que en E.castellani y $\boldsymbol{E}$. dematitidis con más, como también tiene cortas anelaciones, pero estas son más anchas y con menos adornos. Fisiológicamente tambien se diferencia de $\boldsymbol{E}$. castellani porque no asimila meso-eritritol y etanol, pero crece con D-glucuronato. E.dermatitidis es diferente de ambas especies pos su incapacidad de crecer con nitratos, nitritos, creatina y creatinina, pero además es la única que crece a $40^{\circ} \mathrm{C}$

(Hasse et al., 1999). Ver Tabla 3.

Exophiala dermatitidis (Kano) de Hoog. (Fig. 1-4)

=Hormiscium dermatitidis Kano, Aichi Igakkai Zasshi

$=$ Fonsecaea dermatitidis (Kano) Carrion

=Hormiscium dermatitidis Kano, Aichi Igakkai Zasshi

$=$ Hormodendrum dermatitidis (Kano) Conant

$=$ Phialophora dermatitidis (Kano) C.W. Emmons

=Wangiella dermatitidis (Kano) McGinnis,

Características de cultivo: En Agar Sabouraud Dextrosa (SDA) incubada a $28-30^{\circ} \mathrm{C}$, colonias de lento crecimiento, inicialmete negras y de aspecto levaduriforme, a menudo con un exudado café en el agar, olivaceas a grises en el tiempo y de aspecto filamentoso (ver Fig. 1). Microscopía. La fase inicial levaduriforme se refiere a su sinanamorfo (Exophiala exophiale (de Hoog) de Hoog =Phaeococcomyces exophialae de Hoog), el cual se caracteriza por células levaduriformes brotantes, unicelulares, ovoides a elipsoides. Las células semejantes a levaduras son hialinas de paredes delgadas cuando jóvenes, luego se pigmentan en el tiempo (dematiaceas) y de paredes gruesas al madurar. Al desarrollarse el micelio, se obsevan fiálides en forma de frasco a cilíndricas con un lago y fragil collarete que puede estar presente. Conidios hialinos a café pálidos, unicelulares, elipsoidales a subcilíndricos, $2-4 \times 2,3 \mu \mathrm{m}$, de paredes lisas y acumulados en masas mucoides (glioconidia), en el ápice de las fíalides o sésiles sobre el micelio. Cuerpos esclerotiales pueden formarse. Cultivos que crecen hasta 40- 420. La habilidad de asimilar melezitosa en las especies del clado spinifera (en el listado de Tabla 1), son de utilidad para diferenciarlas de $\boldsymbol{E}$. dermatitidis.

Es la especie más termotolerante y no asimila los nitritos, ver Tabla 2 y 3 ).

(E. exophialae. =Phaeococcomyces exophialae de Hoog), fue introducido originalmente como una especie bajo un paragua morfológico que cubría estrictamente células levaduriformes con algunas hifas indiferenciadas,que no se asignó a ninguna especie de Exophiala conocida (De Hoog, 1977). De Hoog et al. (1995). notaron que $\boldsymbol{E}$. exophialae y $\boldsymbol{E}$. spinifera son idénticas en su patrones fisiológicos, incluyendo su habilidad de crecer a $37^{\circ} \mathrm{C}$. En sus secuencias ITS, las 3 cepas conocidas de $P$. exophialae eran también estrechamente relacionadas pero significativamente

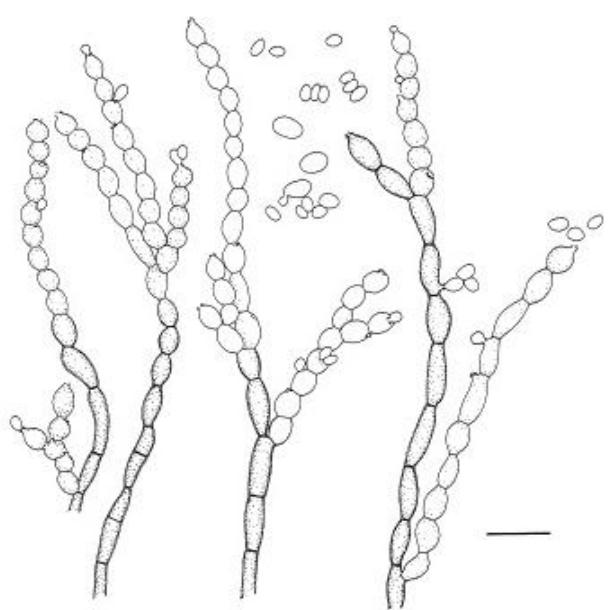

Fig.3. E.bergeri. Hifas toruloides y células gemando con zonas aneladas cortas (Tomado de: Haase \& de Hoog, Studies in Mycology, 43: 91, 1999)

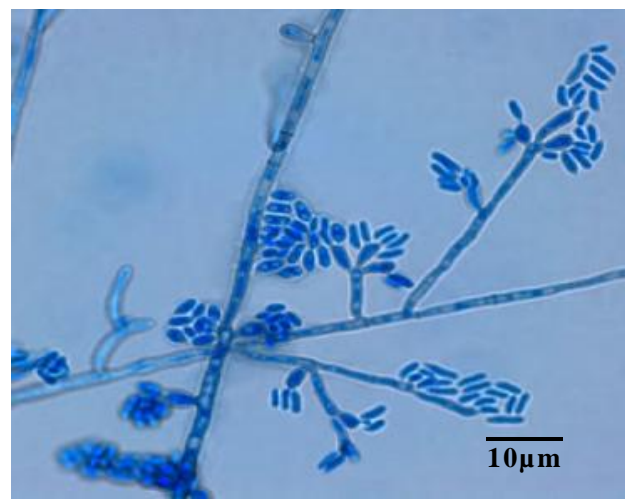

Fig.4. E. dermatitidis, conidióforos y conidios (Tomada de: thunderhouse4yuri.blogspot.com/2012/07/exophialadermatitid - 115k) 
Diversidad y polimorfismo en el género Exophiala: manejo de las especies comunes en el laboratorio de baja complejidad -E. Piontelli.

diferentes de $\boldsymbol{E}$. spinifera y se sugirió que podría haber 2 especies en el complejo (De Hoog et al., 1999). La combinación en Exophiala se confirmó morfológicamente debido a que las 2 cepas reconocidas posteriormente como $\boldsymbol{E}$. exophialae, en base a datos secuenciales, no eran estrictamente semejante a levaduras, pero producen un anamorfo anelídico consistente con el género Exophiala. Este anamorfo carece de estructuras características que pueden permitir su identificación basándose en la microscopía. Como diferencia de $\boldsymbol{E}$. spinifera, en $\boldsymbol{E}$. exophialae nunca se han encontrado conidióforos bien diferenciados. Debe recalcarse, sin embargo, que pocas cepas identificadas como $E$. spinifera por sus secuencias de ITS carecen de conidióforos diferenciados (De Hoog et al., 2003). La relación taxonómica entre E.dermatitidis y $\boldsymbol{E}$. mansonii no ha sido posible confirnarla, sin embargo, los resultados de Chee \& Kim, 2002 demuestran que estas 2 especies son genéticamente muy similares.

El clado dematitidis incluye otras especies de Exophiala tales como: $\boldsymbol{E}$, heteromorpha, E. protrotropha, E. phaeomuriformis, Capronia munkii, C.mansonii, C. epimyces y Ramichloridium makenziei (De Hoog et al., 2011).

\section{E. jeanselmei Langeron Mc Ginnis \& Padhye (Fig. 5-6) \\ $=$ Torula jeanselmei Langeron \\ $=$ Phialophora jeanselmei (Langeron) C.W. Emmons \\ $=$ Pullularia jeanselmei (Langeron) C.W. Dodge \\ $=$ Torula jeanselmei Langeron \\ $=$ Exophiala jeanselmei var. jeanselmei}

Características de cultivo. En agar Sabouraud, colonias inicialmente lisas,verde-grisáceas a negras, mucoides y semejantes a lavaduras, se tornan levantadas y desarrollan manojos de hifas aéreas. Reverso oliváceo a negro. Microscopía. Numerosas células brotantes elipsoidales semejantes a levadura usualmente presentes especialmente en cultivos jóvenes, entremezcladas entre las células semejantes a levaduras usualmente presentes,especialmente en cultivos jóvenes, entremezcladas entre las células semejantes a levaduras, se presentan células largas, infladas, subglobosas a ampliamente elipsoidales (células germinales), que dan origen a cortas y torulosas hifas que gradualmente cambian a hifas no brotantes. Células conidiógenas en hifas intercalares o en forma de cohete, con inconspicuas zonas aneladas. Conidios hialinos, lisos, de paredes delgadas, ampliamente elipsoidales, 2,6- 5,9 $\times 1,2-2,5 \mu \mathrm{m}$, con una cicatriz basal incospicua. Cultivos crecen a $37^{\circ} \mathrm{C}$ pero no a $40^{\circ} \mathrm{C}$. Distribución mundial, pero principalmente en Asia.

(E. jeanselmei, se ha reconocido como una especie heterogénea desde mucho tiempo. Basándose en su morfología de Hoog 1977, reconoció 3 variedades que actualmente se consideran especies separadas y distantemente relacionadas (Wang et al., 2001). Las cepas semejantes a $\boldsymbol{E}$. jeanselmei puden mostrar 2 diferentes fenotipos: uno anelídico, como en Exophiala y otro simpodial, como en Rhinocladiella (De Hoog, 1977). En Rhinocladiella atrovirens (Nannf.) de Hoog, los 2 tipos de conidiogénesis pueden observarse aún en una misma hifa. Por esta razón De Hoog et al. (2003), en un estudio taxonómico de especies clasificadas en Rhinocladiella y Ramichloridium, incluyendo algunos aislados no descritos, aportan nuevas especies como Exophiala oligosperma, Ramichloridium basitonum y Rhinocladiella similis. Exophiala jeanselmei se redescribe, se proponen nuevas combinaciones y se designa Exophiala heteromorpha para $E$. jeanselmei var. heteromorpha. E.oligosperma y $E$, xenobiotica, son fenotípicamente similares a $\boldsymbol{E}$. jeanselmei y se confunden frecuentemente con este taxon, sin embargo, genéticamente son muy diferentes (Badali et al., 2010). Ver Tabla 3.

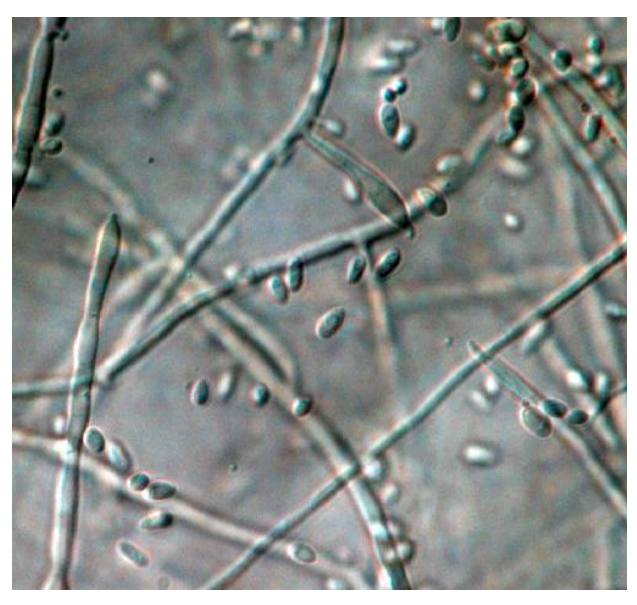

Figura 5. E. jeanselmei.Conidios dispersos y células conidiógenas en forma de cohete.

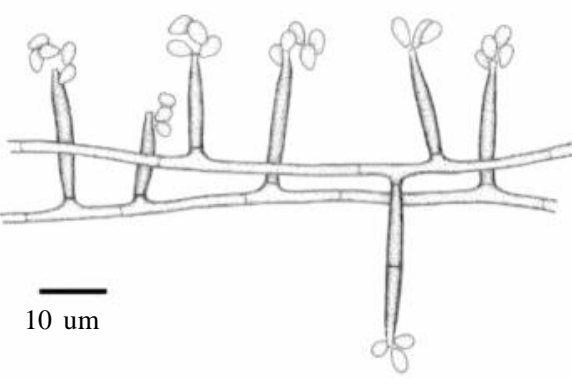

Figura 6. Exophiala jeanselmei, mostrando sus típicas células conidiógenas en forma de cohete en su talo maduro (Dibujo tomado de: de De Hoog et al., 2003). 
El clado Jeanselmei, contiene un amplio número de especies tales como E. nigra, E. bergeri, E.xenobiótica, E. nishimurae, E. oligosperma, E. exophiale, $E$. spinifera $E$. lecanii-corni, $E$. mesophila $E$. castellani, entre otros taxa relacionados (Kawasaki et al., 2005; de Hooh et al., 2011)

Exophiala lecanii-corni (Benedek \& G. Specht) Haase \& de Hoog (Fig.7). $=$ Torula lecanii-corni Benedek \& G. Specht: 86, 1933

$=$ Exophiala jeanselmei var. lecanii-corni (Benedek \& G. S...

$=$ Pullularia fermentans var. benedekii E.S. Wynne \& Gott,...

=Hormodendrum negroni

Caracteristicas de cultivo. Colonias en SGA, restringidas, secas, aterciopeladas, en algunas zonas, pulverulentas, griseses a oliváceas.

Microscopía. Algunas levaduras generalmente escasas. Hifas oliváceas pálidas, profusamente ramificadas, que en su parte apical presentan coherentes cadenas de células conidiógenas en forma de barrill de hasta $6 \mu \mathrm{m}$ de ancho, interconectadas con delgados y anchos septos. Las cadenas se elongan acropetalmente desde una ancha base. Cicatrices conidiales amplias y planas, que producen pocos conidios en forma basípeta 0 mas o menos en orden simpodial se tornan de color café. Conidios ampliamente elipsoidales, 5,5 -9 × 3-4,5 $\mu \mathrm{m}$, contínuos 0 con un un septo delgado, subhialinos, que con el tiempo se tornan café oscuros y de paredes gruesas. Células infladas semejante a clamidosporas hasta $15 \mu \mathrm{m}$, ocasionalmente presentes. Temperatura maxima de crecimiento $36^{\circ} \mathrm{C}$ (debil).

(De Hoog, 1977), introdujo algunas variedades de $\boldsymbol{E}$. jeanselmei, que actualmente se reconocen como especies separadas como; var. Iecanii-corni, var. heteromorpha (ver Hasse et al., 1999; De Hoog et al., 2006).Ver Tabla 3.

Exophiala xenobiotica de Hoog, Zeng, Harrak \& D. A. Sutton (Fig.8-9).

Características de cultivo. Colonias en PDA y MEA incubdas a $27^{\circ} \mathrm{C}$ por 14 d., restringidas, circulares, que se inician al tercer día, planas, olivaceas, negras, mucosas, con el centro oliváceo-gris y márgenes planos, a los 14 días se hacen umbonadas, aterciopeladas, olivaceas-grises, con un centro café-gris. Reverso olivaceo-negro en MEA, negro en PDA, sin pigmentos difusibles. Microscopía. Células gemando inicialmente abundantes, olivaceas-pálidas, elipsoidales, 5-6 x 2,5-3 $\mu \mathrm{m}$, sin capsula en tinta china, a menudo infladas que en el tiempo se transforman en ampliamente elipsoidales. Células germinativas café de aproximadamente 7-10 x 3-5 $\mu \mathrm{m}$, que a menudo originan una corta e irregular zona anelada. Hifas oliváceas a café, 1,3- $2 \mu \mathrm{m}$ de ancho, irregularmente septadas cada 7-28 $\mu \mathrm{m}$. Anastomosis abundantes, conidioforos con 1-7 células, que nacen en ángulo agudo 0 derecho desde hifas crecientes, con el mismo color de la hifa, a menudo ramificadas. Células conidiógenas en forma de limón 0 fusiformes, con una irregular zona anelada. Conidios que se adhieren en pequeños grupos, subhialinos, obovoidales, 3,3- 4 ×1,6-2 $\mu \mathrm{m}$. Clamidosporas esféricas, subhialinas de hasta $13 \mu \mathrm{m}$, pueden estar presentes. Teleomorfos ausentes en el tiempo. Temperatura: óptimo $30^{\circ} \mathrm{C}$, maxima $33-36^{\circ} \mathrm{C}$.

$\boldsymbol{E}$. xenobiotica pertenece al clado 3 y es parafilética a $\boldsymbol{E}$. spinifera, $\boldsymbol{E}$. jeanselmei y $\boldsymbol{E}$. oligosperma (De Hoog et al., 2006). Al igual que $\boldsymbol{E}$. jeanselmei y $\boldsymbol{E}$. oligosperma, la especie $\boldsymbol{E}$. xenobiotica tiene células conidiógenas fusiformes insertadas lateralmente en las hifas, con una única zona anelada terminal, que es a menudo irregularmente acampanada. La especie es indistinguible de $\boldsymbol{E}$. oligosperma y de las colonias inmaduras de $\boldsymbol{E}$. jeanselmei en morfología y fisiología. Las células conidiógenas maduras de $\boldsymbol{E}$. jeanselmei nacen en ángulo recto desde hifas progresivas y son algo 0 más oscuras que el talo remanente (De Hoog et al. 2000). De hecho, E.xenobiotica ha sido aislada solo excepcionalmente de animales, todos

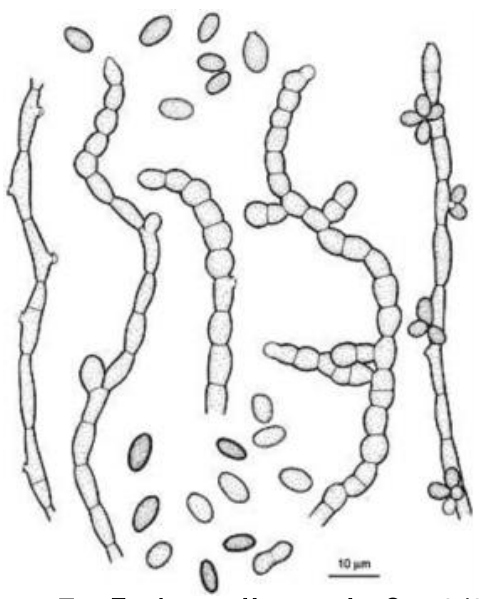

Figura 7. E. lecanii-corni. Conidios elipsoidales, con mas omenos pro-dución de anélides; frecuentemente se observan cadenas de células en forma de barril.(Figura tomada de: De Hoog et al., 2000)

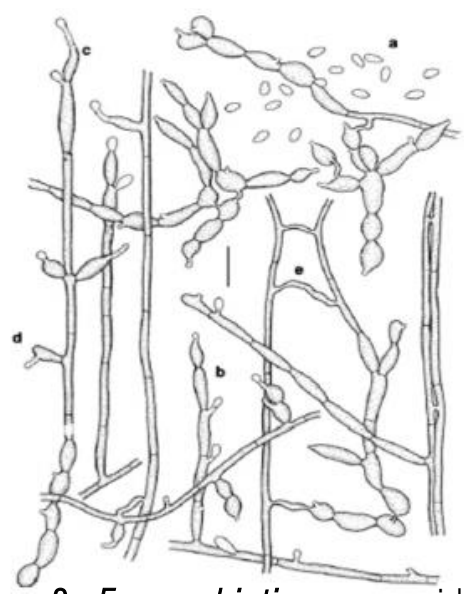

Figura 8. E. xenobiotica. a. conidios, b. conidióforos, c. células conidiógenas, e. anastomosis Barra $10 \mu \mathrm{m}$. (Tomado de. de Hoog et al. 2006)

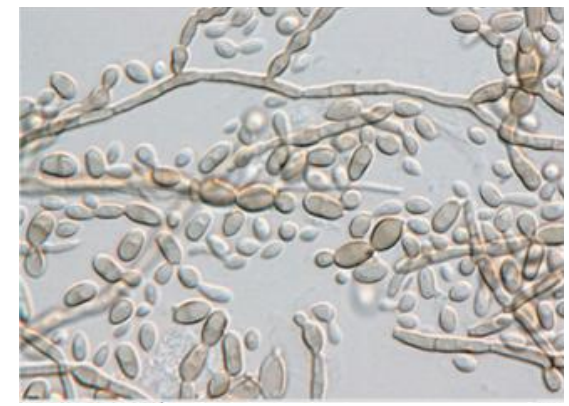

Figura 9. Exenobiótica en PDA a $25^{\circ} \mathrm{C}$, conidios y células conidiógenas (Tomada de:drmtl.org/data/121010011j.pd. 日皮会誌：121（1）１1-16，2011（平成 23） 
Diversidady polimorfismo en el género Exophiala: manejo de las especies comunes en el laboratorio de baja complejidad -E. Piontelli.

los hospedadores de hecho, son de sangre caliente. Sin embargo, los síntomas clínicos son predominantemente y moderadamente cutáneos. Varias de las cepas ambientales derivan de ambientes humedos, como fluidos de diálisis, desinfectantes de instrumental de endoscopía y de pisos de baño. Las cepas resisten la luz UV, sobreviven varias descontaminaciones con ácido paracético y peroxido de hidrógeno, así como puede subsistir a pH 1 (Hölker et al.,2003). E. xenobiotica y $\boldsymbol{E}$. oligosperma, son las especies más frecuentes como oportunistas en humanos que causan infecciones sistémicas y cutáneas (Zeng et al. 2007).

Exophiala spinifera (H.S. Nielsen \& Conant) McGinnis (Fig. 10-11) $=$ Phialophora spinifera H.S. Nielsen \& Conant $=$ Rhinocladiella spinifera (H.S. Nielsen \& Conant) de Hoog

Características de cultivo. Colonias inicialmente mucoides y semejantes a levaduras negras, que se tornan solevantadas, desarollando cordones de micelio aéreo en el tiempo, finalmente se tornan atrciopeladas a vellosas en textura. Reverso oliváceo negro. Microscopía. Conidióforos únicos 0 ramificados, erectos 0 suberectos, semejantes a espinas, con más bien una pared gruesa y pigmentada de café. Conidios formados en sucesión basípeta sobre peg laterales que nacen apicalmente 0 lateralmente en ángulo agudo de los conidióforos, semejante a espinas o desde hifas indiferenciadas. Los peg conidiógenos son 1-3 $\mu \mathrm{m}$ de largo, que se adelgazan levemente hacia el ápice e inperceptiblemente anelados. Conidios unicelulares, subhialinos, lisos, de paredes delgadas, subglobosos a elipsoidales, 1-2,9 x $1,8-2,5 \mu \mathrm{m}$, agregados en racimos en el ápice de cada anélide. Se presentan típicamente hifas toruloides y células semejantes a levadura con conidios secundarios.

Los estudios moleculares por Vitale \& de Hoog (2002), al reexaminar E. spinifera, reconocieron que el clado contiene varias especies con mas o menos células condiógenas diferenciadas: $\boldsymbol{E}$. spinifera y $\boldsymbol{E}$. attenuata son muy similares morfológicamente y se distinguen mejor por análisis genéticos, sin embargo, esta última es una distante contraparte de E.spinifera y se ubica fuera de su clado. Las células conidiógenas son predominantemente anelídicas y erectas, conidióforos multicelulares se presentan tan oscuros como las hifas soportantes. No crece a $40^{\circ} \mathrm{C}$. En $\boldsymbol{E}$. spinifera, las largas zonas aneladas son claramente visibles, con anelaciones con depósitos, mientras en $\boldsymbol{E}$. attenuata las zonas aneladas son incospicuas y degeneradas. $\boldsymbol{E}$. jeanselmei y $\boldsymbol{E}$. oligosperma, tienen células conidiógenas no septadas en forma de cohete, levemente oscuras. E.spinifera, es causa poco frecuente de feohifomicosis en pacientes inmunodeprimidos. En pacientes sanos la infección se puede desarrollar tras la implantación traumática del hongo.

Exophiala oligosperma Calendron ex De Hoog \& Tintelno (Fig. 12-13-14). $=$ Melanchlenus oligospermus Calendron

Características de las colonias. Colonias restringidas en PDA a $28^{\circ} \mathrm{C}$ después de 10 días; inicialmente mucoides y levemente arrugadas en el centro, posteriormente desarrollan micelio aéreo flocoso oliváceo-gris a cafénegro. Reverso oliváceo-negro. Colonias en MEA,aterciopeladas, oliváceasgrises y secas, generalmente con una insignificante fase levaduriforme. Sin pigmento difusible en ambos medios. Microscopía. Células brotantes abundantes, oliváceas pálidas, ampliamente elipsoidales, $3 \times 2,5 \mu \mathrm{m}$, sin cápsula en tinta china, a menudo infladas, que se desarrollan en células café que germinan de forma ampliamente elipsoidales, $6 \times 5 \mu \mathrm{m}$, que a menudo originan zonas aneladas cortas e irregulares. Hifas pálidas olivaceas a café, a veces infladas, 1,5 a 3,2 $\mu \mathrm{m}$ de ancho, irregularmente septadas cada 20 a $40 \mu \mathrm{m}$. Células conidiógenas que generalmente nacen en ángulo agudo como

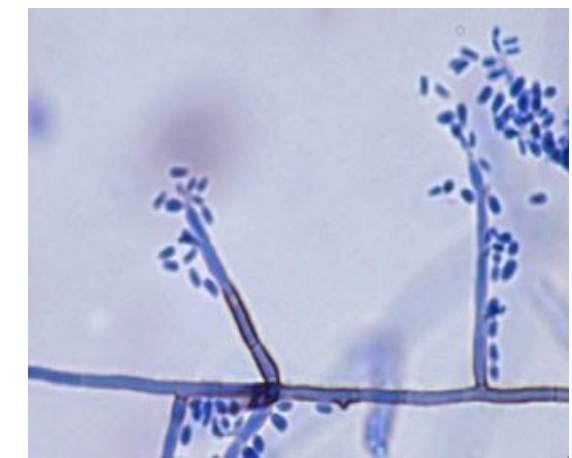

Figura 10. E. spinifera, conidióforos, zonas aneladas y conidios (Figura tomada de: University of Adelaide, Mycology Online).

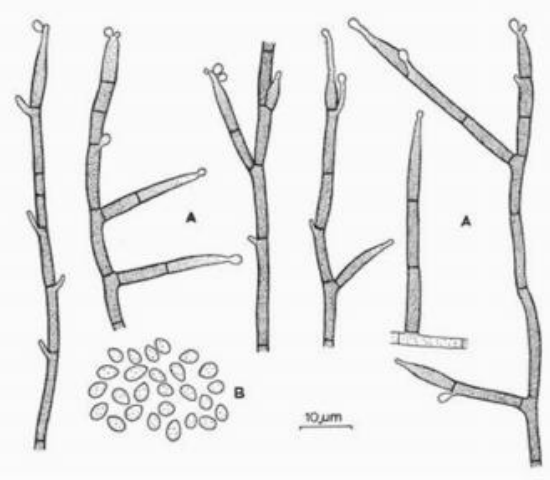

Figura 11. Exophiala spinifera, A aparatos conidiales, B Conidios (Tomada de: De Hoog, 1977)

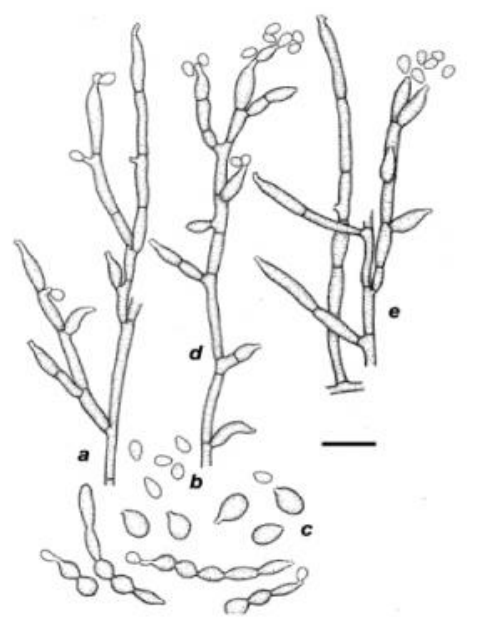

Figura 12. E. oligosperma CBS 245.49, mostrando el aparato coni-dial (a y e), conidios (b) y células germinando (c). (d) E. jeanselmei UTMB, mostrando su inmaduro aparato conidial. Barra $10 \mu \mathrm{m}$. (Tomado de: De Hoog et al, 2003). 
Diversidad y polimorfismo en el género Exophiala: manejo de las especies comunes en el laboratorio de baja complejidad -E. Piontelli.

parte de un aparato conidial poco diferenciado, tambien nacen en ángulo recto desde hifas progresivas. Ramas conidiales son del mismo color de la hifa o solo levemente oscuras en una a 3 células; la última célula tiene forma de cohete 0 asciende angostándose en forma de cohete 0 asciende angostándose en forma cilíndrica, con zonas aneladas irregularmente. Conidios que adhieren en pequeños grupos de color subhialino, obovoidales, 3- 5x 2,2- 3,2 $\mu \mathrm{m}$. Clamidosporas esféricas, subhialinas hasta $13 \mu \mathrm{m}$ en diámetro pueden estar presentes. Teleomorfo desconocido. No crece a $35^{\circ} \mathrm{C}$.

Las cepas ambientales se agrupan en este clado y la mayoría se obtienen desde sustancias con bajos nutrientes o sustratos azucaracdos, tales como la miel, silicona 0 sobre superficies húmedas en materiales inertes, en saunas o piscinas. Muchos casos reportados como nosocomiales (infecciones cerebrales, keratitis, bursitis, micetoma, etc.), se originaron por aguas de hospitales contaminadas causando fungemias por $\boldsymbol{E}$. jeanselmei, (Nucci et al., 2002), posteriormente fueron clasificadas como E.oligosperma por secuencias de ITS. Lo que demuestra una aparente union entre la contaminación por agua y su oportunismo en humanos. A semejanza de los miembros del grupo $\boldsymbol{E}$. jeanselmei, tienen células conidiógenas en forma de cohete insertadas lateralmente en las hifas con una única zona anelada terminal que a menudo es irregularmente desarrollada. La especie puede ser fenéticamente sililar a $\boldsymbol{E}$. jeanselmei y se confunde generalmente con este taxón. Cuando las 2 especies son menos diferenciadas, pueden ser morfológicamente indistinguibles, sin embargo, en sus caracteristicas de cultivo, las células conidiógenas de $\boldsymbol{E}$. jeanselmei, nacen en ángulo recto desde hifas progresivas y son un tanto más oscuras que el micelio remanente. Las secuencias de ITS, permiten separar claramente las 2 especies, una situación que es el diagnóstico estandard para las levaduras negras. Muchas cepas de $\boldsymbol{E}$. oligosperma, son fuertemente semejantes a levaduras y por ende no son morfológicamente distintivas. Las zonas aneladas en $\boldsymbol{E}$. oligosperma es corta e irregular, mientras en $\boldsymbol{E}$.. jeanselmei es pronounciada y que se va estrechando, con anelaciones que son prácticamente invisibles a la luz del microscopio $\boldsymbol{E}$. nishimurae es morfológicamente idéntica a $\boldsymbol{E}$. oligosperma y también produce grandes clamidosporas, sin embargo, no asimila eritritol (Vitale \& de Hoog, 2002), a diferencia de E. oligosperma y E. jeanselmei (De Hoog et al., 1995).(Ver también De Hoog et al., 2003 y Tabla 3).

Pequena reseña morfológica del los principales integrantes del grupo E.jeanselmei

E. jeanselmei. Células conidiógenas maduras en forma de cohete, levemente más oscuras que las hifas de soporte, con zonas aneladas que se adelgazan hacia el ápice.

E. oligosperma. Células conidiógenas maduras que permanecen del mismo color que las hifas soportantes y pueden ser intercalares y laterales, las últimas pueden tener forma de frasco 0 cohete. Las zonas aneladas tienen la apariencia de inconspicuas cicatrices planas.

E. nishimurae. Tiene la similar morfología que $\boldsymbol{E}$. oligosperma, sin embargo, se presentan grandes células semejantes a clamidosporas.

E. xenobiotica. Un genotipo segregante del complejo E. jeanselmei con células conidiógenas menos melaninizadas.

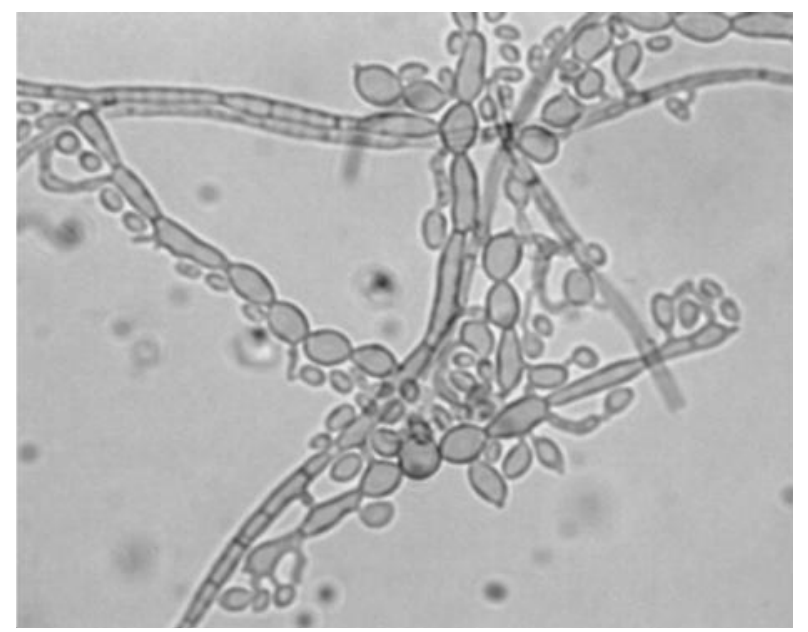

Figura 13. E. oligosperma. Hifas verdaderas (en lo alto), células infladas de seudohifas (izquierda) y aneloconidios desde prominentes locus conidiógenos intercalares (derecha) (Figura tomada de: Bossler et al., 2003).

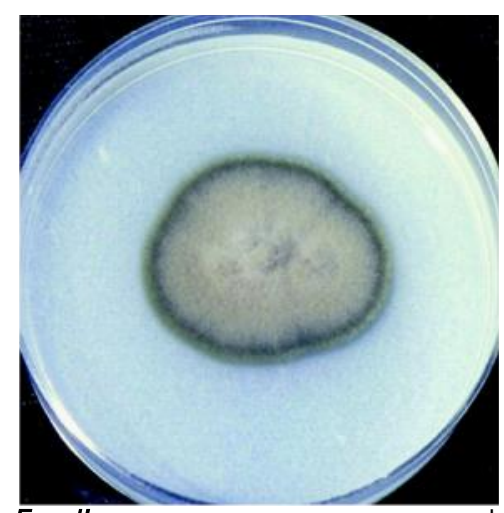

Figura 14. E. oligosperma en agar escamas de papa durante 16 días a $25^{\circ} \mathrm{C}$ (Figura tomada de: Bossler et al., 2003).

\section{REFERENCIAS}

Badali, H; Najafzadeh, MJ; van Esbroeck M, et al.,(2010) The clinical spectrum of Exophiala jeanselmei, with a case report and in vitro antifungal susceptibility of the species. Med. Mycol. 48:318-327

Biedunkiewicz A. \& Schulz, A. (1012). Fungi of the genus Exophiala in tap water - potential etiological factors of phaeohyphomycoses. Mikologia Lekarska 19:23-26 
Diversidad y polimorfismo en el género Exophiala: manejo de las especies comunes en el laboratorio de baja complejidad - E. Piontelli.

Boeger, W.A.; Pie, R.M.; Ostrensky, A. \& Patella L. (2005). Lethaargic crab disease: multidisciplinary evidence supports a mycotic etiology. Memorias Instituto Oswaldo Cruz, Rio de Janeiro 100:161-167

Boeger, W.A.; Pie, R.M.; Vicente, V.; Ostrensky, A.; Hungria, D.; Castilho, G.G. Histopathology of the mangrove land crab Ucides cordatus (Ocypodidae) affected by lethargic crab disease. Diseases of Aquatic Organisms 78:73-81

Bossler,A.D.; Richter, S.S.;Chavez,A.J. et al., (2003). Exophiala oligosperma causing olecranon bursitis. J. Clin. Microbiol. 41:4779-4782

Calvo, E.; Pastor, F.J \& Guarro, J. (2010).Antifungal therapies in murine disseminated phaeohyphomycoses caused by Exophiala species. J. Antimicrob. Chemother. 65:1455-1459

Carmichael, J.W. (1966). Cerebral mycetoma of trout due to a Phialophora-like fungus. Sabouraudia 6:120-123

Chee, H.Y. \& Kim. Y-K. (2002). Molecular Analysis of Exophiala Species Using Molecular Markers. Mycobiology $30: 1-4$

De Hoog, G. S. (1977). Rhinocladiella and allied genera. Stud. Mycol. 15:1-144

De Hoog, G. S., A. H. G. Gerrits van den Ende, J. M. J. Uijthof, and W. A.Untereiner. 1995. Nutritional physiology of type isolates of currently accepted species of Exophiala and Phaeococcomyces. Antonie Leeuwenhoek 68:43-4

De Hoog, G. S., \& G. Haase. 1993. Nutritional physiology and selective isolation of Exophiala dermatitidis. Antonie Leeuwenhoek 64:17-26.

De Hoog, G. S.; J. M. J. Uijthof.; A. H. G. Gerrits van den Ende.; M. J. Figge,; X. O. Weenink. (1997). Comparative rDNA diversity in medically significant fungi. Microbiol. Cult. Collect. 13:39-48

De Hoog, G. S.; Takeo, K.; Yoshida, S.; Gottlich, E.; Nishimura, K.; Miyaji. M. (1994). Pleoanamorphic life cycle of Exophiala (Wangiella) dermatitidis.Antonie Leeuwenhoek 65:143-153

De Hoog, G. S.; Poonwan, N.\& Gerrits A.H.G van den Ende. (1999). Taxonomy of Exophiala spinifera and its relationship to $E$. jeanselmei. Stud. Mycol. 43:133-142

De Hoog, G. S., J. Guarro, J. Gene', \& M. J. Figueras. (2000). Atlas of clinical fungi, 2nd ed. Centraalbureau voor Schimmel-cultures, Utrecht, The Netherlands.Universitat Rovira y Virgili, Reus, Spain.

De Hoog, G. S.; Vicente, E.; Caligiorne, R.B.; Kantarcioglu, B.; Tintelnot, K.; Gerrits A.H.G. van den Ende.; Haase.G. (2003). Species diversity and polymorphism in the Exophiala spinifera clade containing opportunistic black yeast-like fungi. J. Clin. Microbiol. 41:4767-4778

De Hoog, G. S.; Zeng,J.S.; Harrak,M. J. \& Sutton. D.A. (2006). Exophiala xenobiotica sp. nov., an opportunistic black yeast inhabiting environments rich in hydrocarbons. Antonie Leeuwenhoek 90:257-268

De Hoog,G.S.; Vicente1,V.A.; Najafzadeh, M.J.; Harrak1, M.J.; Badali, H.; Seyedmousavi, S. (2011). Waterborne Exophiala species causing disease in cold-blooded animals. Persoonia 27:46-72

Florent, M.; Le, J-L.B.; Dea, G-H. et al., (2012). Phaeohyphomycosis due to Exophiala xenobiotica as a cause of fungal arthritis in an HIV-infected patient. Medical Mycology 50:513517

Gerrits van den Ende, A.H.G. \& Hoog, G.S. de. (1999). Variabi-lity and molecular diagnostics of the neurotropic species Cladophia-Iophora bantiana. Studies in Mycology 43:151-162

Göttlich, E.; Lubbe, W. van der.; Lange, B,.; Fiedler, S.; Melchert, I. et al. (2002). Fungal flora in groundwater-derived public drinking water. International Journal of Hygiene and Environmental Health 205:269-279

Kawasaki, M.; Anzawa,K.; Tanabe, H. et al., (2005). Intra.species variation of genotypes in Exophiala jeanselmei isolated from patient in Japan. Jpn. J. Med. Mycol. 46:261265

Haase, G.; Sonntag,L.; Melzer-Krick, B. \& De Hoog, G.S. (1999). Phylogenetic nference by SSU-gene analysis of members of the Herpotrichielllaceae with special reference to human pathogenic species. Stud. Mycol. 43:80-97

Harris, J.E.; Suttopn, D.A.; Rubin, A. et al., (2009). Exophiala spinifera as a Cause of Cutaneous Phaeohyphomycosis: Case Study and Review of the Literature. Med. Mycol. 47:87-93

Hölker, U.; Bend, J.; Pracht, R.; Müller, T.; Tetsch, L.; De Hoog, G. S. (2003). Hortaea acidophila, a new acidophilic black yeast from lignite. Antonie van Leeuwenhoek 86:287294

Hong,, K.H.; Jeong Won Kim, J.W.; Jang, S.J. et al., (2009). Eunsil Yu2 and Eui-Chong Kim1 Liver cirrhosis caused by Exophiala dermatitidis J. Med. Mycol 58:674-677

Horre, R. \& de Hoog, G.S. (1999). Primary cerebral infections by melanized fungi: a review. Stud. Mycol. 43:176-193

Kawasaki, M.; Anzawa, K.; Tanabe, H.; Mochizuki, T. ; Ishizaki, H.; Nishimura, K. (2005). Intra-species variation of genotypes of Exophiala jeanselmei isolated from patients in Japan. Nihon Ishinkin Gakkai Zasshi 46:261-265. 
Diversidad y polimorfismo en el género Exophiala: manejo de las especies comunes en el laboratorio de baja complejidad -E. Piontelli.

Langvad, F.; Pedersen, 0.; Engjom, K. (1985). A fungal disease caused by Exophiala sp. nov. in farmed Atlantic salmon in Western Norway. In: Ellis AE (ed), Fish and shellfish pathology. Academic Publishers, London.

Li,D.M.; Li, R.Y.; Hoog GS de, Wang, Y.X. \& Wang, D.L. (2009). Exophiala asiatica, a new species from a fatal case in China. Medical Mycology 47:101-109.

Lian, X. \& de Hoog, G.S. (2010). Indoor wet cells harbour melanized agents of cutaneous infection. Med. Mycol. 48:622-628.

Liu, S.M; \& Siah,S.P. (2011). Exophiala. In:Molecular detection of human fungal pathogen (Liu, D. Editor) CRS Press. Chapter $31: 247-256$

Matos, T.; de Hoog, G.S.; de Boer, A.G.; de Crom, I.; Haase, G. (2002). High prevalence of the neurotrope Exophiala dermatitidis and related oligotrophic black yeasts in sauna facilities. Mycoses 45:373-377

Matsumoto, T.; Matsuda, T.; McGinnis, M. R. \& Ajello, L. (1993). Clinical and mycological spectra of Wangiella dermatitidis infections. Mycoses 36:145-155

Morio, F;; Le Berre,J-Y.; Garcia-Hermoso.D, et al., (2012). Phaeohyphomycosis due to Exophiala xenobiotica as a cause of fungal arthritis in an HIV-infected patient Med. Mycol. DOI: 10.3109/13693786.2011.648218

Naka, W.; Harada, T.; Nishikawa, T. \& Fukushiro.R. (1986). A case of chromoblastomycosis with special reference to the mycology of the isolated Exophiala jeanselmei. Mykosen 29:445-452

Neumeister, B.; Zollner, T.M.; Krieger, D.; Sterry,W.; Marre. R. (1995).Mycetoma due to Exophiala jeanselmei and Mycobacterium chelonae in a 73-year- old man with idiopathic CD4 T lymphocytopenia. Mycoses 38:271-276

Nucci, M.; Akiti, T.; Barreiros,G.; Silveira,F.; Revankar, S.G.; Wickes, B.L.; Sutton, D.A.; Patterson.T.F. 2002. Nosocomial outbreak of Exophiala jeanselmei fungemia associated with contamination of hospital water. Clin. Infect. Dis. 34:1475-1480

Ozawa, Y.; Suda, T.; Kaida, Y., et al., (2007). A case of bronchial infection of Wangiella dermatitidis. Nihon Kokyuki Gakkai Zasshi 45:907-911 (en Japones).

Oztas,E.;Odemis,B.;Kekilli,M.;Kurt,M et al.,(2009). Systemic phaeohyphomycosis resembling primary sclerosing cholangitis caused by Exophiala dermatitidis. J. Med. Microbiol. 58:1243-1246

Pedersen, O.A. \& Langvad, F. (1989). Exophiala psychrophila sp. nov., a pathogenic species of the black yeasts isolated from Atlantic salmon. Mycological Research 92:153-156
Porteous,N.B.;Grooters, A.M.; Redding, S.W. et al., (2003). Identification of Exophiala mesophila Isolated from Treated Dental Unit Waterlines. J. Clin. Microbiol. 41:3885-3889

Prenafeta-Boldú, F,X.; Summerbell, R. \& Hoog, G.S. de. (2006). Fungi growing on aromatic hydrocarbons: biotechnology's unexpected encounter with biohazard? FEMS Microbiological Reviews 30:109-130

Saccardo PA. 1883. Sylloge Fungorum (Abellini) 2:288

Satow, M.M.; Attili-Angelis,D.; de Hoog, G.S.et al., (2008). Selective factors involved in oil flotation isolation of black yeasts from the environment. Stud. in Mycol.y 61:157-163

Saunte DM, Tarazooie B, Arendrup MC, Hoog GS de. (2011). Melanized fungi in skin and nail: it probably matters. Mycoses. doi:10.1111/j.1439-0507.2011.02055.x.

Suh, M.K.; Lee, H.C.; Kim, D.M.; Ha, G.Y.; Choi, J.S. (2012). M.Molecular Phylogenetics of Exophiala Species Isolated from Korea. Ann. Dermat. 24:287-294

Tintelnot, K.; De Hoog, G. S.; Thomas, E.;Steudel, W-I.; Huebner, K.; Seeliger.H.P.R. (1991). Cerebral phaeohypho-mycosis caused by an Exophiala species. Mycoses 34:239-244

Tseng, P. H.; Lee, P.; Tsai, T. H. \& Hsueh, P. R. (2005). Central venous catheter-associated fungemia due to Wangiella dermatitidis. J, Formos. Med. Assoc. 104:123-126

Vicente, VA.; Attili-Angelis, D.; Pie ,M.R.; Queiroz-Telles, F, Cruz, L.M, Najazzadeh, M,J.; Hoog, G.S. de.; Pizirani-Kleine, A.R. (2008). Environmental isolation of black yeast-like fungi involved in human infection. Studies in Mycology 61:137-144

Vitale, R. G., \& G. S. De Hoog. (2002). Molecular diversity, new species and antifungal susceptibilities in the Exophiala spinifera clade. Med. Mycol. 40:545-556

Wang, L.; Yokoyama, K.; Miyaji, M. \& Nishimura, K. (2001). Identification, classification, and phylogeny of the pathogenic species Exophiala jeanselmei and related species by mitochondrial cytochrome b gene analysis. J. Clin. Microbiol. 39:4462-4467

Woo, C.Y.P.; Ngan, H.I.A.; Chris C. C.; Tsang, C.C.C. et al., (2013). Clinical Spectrum of Exophiala Infections and a Novel Exophiala Species, Exophiala hongkongensis. J. Clin. Microbiol. 51:260-267

Yurlova, N.A. \& de Hoog, G.S.(2002). Exopolysaccharides and capsules in human pathogenic Exophiala species.

Mycoses 45:443-448

Zalar, P.; Novak, M.; de Hoog, G.S.; Gunde-Cimerman, N. (2011). Dishwashers- a man-made ecological niche accommodating human opportunistic fungal pathogens. Fungal Biol. 115:997-1007 
Zeng, J.S.; Sutton, D.A.; Fothergill, A.W.; Rinaldi, M.G.; Harrak, M.J.; de Hoog. G. S. (2007) .Spectrum of Clinically Relevant Exophiala Species in the United States. J Clin. Microbiol. 45:37133720

Zeng, J.S \& De Hoog, G.S. (2008). Exophiala spinifera and its allies: diagnostics from morphology to DNA barcoding. Med Mycol 46:193-208.

\section{CONFLICTO DE INTERESES}

El Autor declara no tener conflictos de intereses.
Zhao, J.; Zeng, J.; Hoog, G.S. de.; Attili-Angelis, D.; Prenafeta-Boldú, F.X. (2010). Isolation of black yeasts by enrichment on atmospheres of monoaromatic hydrocarbons. Microbial Ecology 60:149-156 